\title{
Using stochastic algorithms for constraining compartmental and markov channel models
}

\author{
Roy Ben-Shalom*1,2 and Alon Korngreen ${ }^{1,2}$
}

\author{
Address: ${ }^{1}$ Mina \& Everard Goodman Faculty of Life Sciences, Bar Ilan University, Ramat Gan, 52900, Israel and ${ }^{2}$ Leslie and Susan Gonda \\ Multidisciplinary Brain Research Center, Bar Ilan University, Ramat Gan, 52900, Israel \\ Email: Roy Ben-Shalom* - bens.roy@gmail.com \\ * Corresponding author
}

from Eighteenth Annual Computational Neuroscience Meeting: CNS*2009

Berlin, Germany. 18-23 July 2009

Published: 13 July 2009

BMC Neuroscience 2009, I0(Suppl I):P35 doi:I0.I |86/I47|-2202-I0-SI-P35

This abstract is available from: http://www.biomedcentral.com/I47I-2202/I0/SI/P35

(C) 2009 Ben-Shalom and Korngreen; licensee BioMed Central Ltd.

Since the work of Hodgkin and Huxley on the squid axon [1], many models were suggested to achieve a more accurate simulations of voltage gated channels and single neurons. In order to check these models, we produced an insilico neuron, recorded its behavior with a voltage clamp experiment and compared the results with a real neuron voltage clamp. In a previous work a Genetic algorithm was used $[2,3]$ to constrain the parameters of the in-silico neuron. In this work we investigated different stochastic algorithms and compared their performances using several models. The algorithms used were different versions of simulated annealing such as simulated quenching, classic simulated annealing [4] and Particle swarm intelligence with varying social models [5]. The stochastic algorithms were applied to constrain the parameters of ion channels modeled with hidden markov models and electrophysiological parameters of whole cell models. We show that there is no all-purpose algorithm that is the best choice for all the models. Additionally, we show that for each group of models there is an algorithm that out-performed all other algorithms.

\section{References}

I. Hodgkin AL, Huxley AF: A quantitative description of membrane current and its application to conduction and excitation in nerve. J Physiol 1952, I 17:500-44.

2. Gurkiewicz M, Korngreen A: A numerical approach to ion channel modelling using whole-cell voltage-clamp recordings and a genetic algorithm. PLoS Comput Biol 2007, 3:el69.
3. Keren N, Peled N, Korngreen A: Constraining compartmental models using multiple voltage recordings and genetic algorithms. J Neurophysiol 2005, 94:3730-42.

4. Kirkpatrick S, Gelatt CD Jr, Vecchi MP: Optimization by Simulated Annealing. Science 1983, 220:67|-680.

5. Eberhart RC, Kennedy JA: A new optimizer using particle swarm theory. Proc 6th Int Symp Micro Mach Human Sci Nagoya, Japan 1995:39-43. 